\title{
Lost in Translation: Heidegger and Ski Jumping in Slovenia
}

\author{
Lev Kreft
}

Department of Philosophy, Faculty of Arts - University of Ljubljana, Slovenia

ABSTRACT

Heidegger developed his non-concept Gelassenheit after World War II. Its meaning remains uncertain and controversial, something different from notions of everyday conversation. In Slovene, however, it has been translated as sproščenost, which is parallel to English 'relaxedness', thus producing hybridity between notions of relaxedness, relaxation and releasement, which is, together with letting-go, a proper English translation of Gelassenheit.

This hybridity was (ab)used for political slogans during the 2004 elections, when Heidegger's term was repeated on and on, until it entered popular discourse as well as other domains such as the economy, culture, and media. This phenomenon was examined by Boris Vezjak in The Relaxed Ideology of Slovenes (The Peace Institute, Ljubljana 2007). Relaxedness-releasement entered sport jargon as well, but Vezjak's book did not cover this field. At first abundant, this term more or less disappeared later. With one exception: in ski jumping, where it became one of the main words used to explain what was missing from Slovenian ski jumping during 2004-2009 period. In Slovenia, ski jumping is a national sport, and the absence of excellence during this long period created additional pressures on athletes and the whole ski jumping commonwealth.

To examine the numerous cases where releasement was used to explain what is wrong with ski jumpers, or what they finally achieved in rare examples of success during that period, the only Slovene sport daily, "Ekipa" (The Team), was consulted for research. This study revealed that releasement was indeed lost in translation, appearing in ads as a signifier without any certain signified, and functioning as a je-ne-sais-quoi of sport performance and excellence. Through cases of repeated use of releasement as mystical and at the same time scientific (instead of relaxation) and colloquial notion (which is relaxedness, even carelessness), we get at inoculation of kinesiological mechanicism and psychological technique with philosophical mysticism.

KEYWORDS releasement, Heidegger, ski jumping

In 2007, Slovene philosopher Boris Vezjak published a book on The Relaxed Ideology of the Slovenes (Vezjak 2007; in Slovene and in English), analysing the political implications of the philosopheme "relaxedness" in Slovenia during the 2004 election year, including its history and aftermath. Reading his book which covered nearly all the angles, but not elite sport ideology of relaxedness, I decided to add this specific chapter. This paper, however, is heavily indebted to Vezjak's approach, his assessment of Heidegger's and Heideggerian political and ideological (ab)use of "relaxedness" under specifically Slovene circumstances. 


\section{Gelassenheit}

Gelassenheit, translated in English as releasement and letting-go, was introduced in Heidegger's thought in 1959 and elaborated under the same title in his book Conversations on a Country Path about Thinking ${ }^{1}$. However complex and deliberately non-conceptual, it depends on some ideas found in stoicism and other Hellenistic traditions, in Christian mysticism, especially that of Meister Eckhardt. It also depends on some versions of philosophical Orientalism, taking non-European philosophical and mystical traditions as a starting point for criticism of European modernity's preoccupation with the central status of man as master of the universe, and technical-utilitarian attitude which turns all things into objects of our domination, not listening to truth of the things themselves and getting rid of any truth of the being ${ }^{2}$.

As rector of Heidelberg University for a short but crucial period at the beginning of Nazi dictatorship, and a member of National Socialist Party from May 1, 1933 until the end of war and of the Party, Heidegger's life after the war, existing in Germany but alive in France, was that of a complex mis-identity: while he knew who he was and what he stood for between the two World Wars, and expressed his credo on that issue abundantly after the WW2, he had to be careful about those issues, or risk being misunderstood by opponents and adherents alike. Under such pressure, he added to his already murky style of thought a flavour of mysticism, including a tendency to get rid of Dasein's identity itself. When his pre-war fan Herbert Marcuse had opportunity to re-establish some kind of relationship with Heidegger, Marcuse visited him first and then sent him a letter (the whole correspondence between Marcuse and Heidegger can be found in Marcuse 1998, pp. 263-267)33. Marcuse proposed that Heidegger cut his Nazi tail in public and thus get back his membership in the philosophical tribe. As we well know, Heidegger did not want to follow this advice. The most astonishing feature of his answer is not his refusal (in the denazification process, he was punished anyway), not even his clumsy and uncanny arguments, including the comparison of the Holocaust with Soviet terrors committed in occupied Germany, later extended to a comparison between agricultural chicken farms with concentration camps. What is really surprising is a feeling of uneasiness and an unheimlich flavour of his self. Why did he become an activist of Nazi politics, and why did he remain a member even after 1934? There were two reasons. One was his belief that this new German nationalist movement could mean a rebirth of Germany and Europe, another was his ambition to become an official philosopher and ideologue of the Nazi movement. While the first mis-identification is a result of his reaction to the aftermath of WW1, initially not very different from those of many others, from Spengler to Pannwitz (who, however, both decided against Nazism), the second reason is a result of his will for power. He did not admit anything in public, and his thought did not change considerably on the first issue; what he tried to get rid of was the second one. This is what brought about releasement and letting-go: the diagnosis of culture and civilization did not change much, but instead of any possible interpretation that a will to power has to intervene, he introduced a counterconcept of activism, a mystical category of religious origin.

Interpretation of Heidegger's meaning and use of Gelassenheit still brings out many troubles. Without burdening ourselves with a solution to this enigmatic non-concept, we can name some of the commentaries with the help of Slovene philosopher Boris Vezjak. Even Ingrid Schuessler, the editor of the German edition of Heidegger's work, admits that to explain releasement is not an easy job,

\footnotetext{
${ }^{1}$ Martin Heidegger, "Conversations on a Country Path about Thinking", in: Discourse on Thinking (trans. by John M. Anderson and E. Hans Freund), Harper and Row, New York 1966 - this edition is old enough to be found rarely enough, but there is another one in print this year (Heidegger 2010).

${ }^{2}$ Meister Eckhart is, of course, often published and interpreted in German literature, but not that often in English. See: Echkart, M. (1981). The Essential Sermons, Commentaires, Treatises, and Defence. London: SPCK.; and Woods, R. (1987). Eckhart's Way. London: Darton, Longman and Todd.

${ }^{3}$ These letters can be found not just once on the web. To name one of home pages containing these letters, we can name one managed by Marcuse's son (http://www.marcuse.org/herbert/pubs/40spubs/47Marcuse Heidegger.html ), which offers Sheila Benhabib's commentary as well.
} 
because we can get at what it does not mean but not to what it could be about: "What the term Gelassenheit should not mean is clear to me in many respects. But at the same time I increasingly less know what we actually talk about." (Heidegger 2001, p. 114). This term has history in Western philosophy, and this history includes Meister Eckhart's mystical philosophy where it means to surrender to God, a mystical state without will of one's own. God is absolutely good and cannot do anything evil, while humans have a kind of freedom God does not possess: a free will to chose between good and evil. Releasement is to get rid of free will, a state of pure commitment to God. On the other side of Heidegger's sources we find Asian philosophies, because his Path (Weg) is close to Dao, while Gelassenheit is close to wu wei (non-action) (Vezjak 2007, p. 92). These encounters with Asian philosophies have been researched many times. Graham Parkes, one of the researchers into the Asian components of Heidegger's thought, says that we have to take into account the stoic concept of dispassion (apatheia) together with Eckhart and Dao. Still, this inclination to mystic traditions is detached from anything religious, such as in the Amish use of Gelassenheit for a calm and quiet state of piety. Here, its roots are in loving God: but what is the object of Heidegger's love, if there is any love at all? If it is a philosophical love for wisdom or truth, it has to mean that neither wisdom nor truth is conceptual and discursive. It definitely has nothing to do with objectification of the world, and it is a state without passions and emotions, but also without any technical appetites that lead to possession of objects and utilitarian relationship with them. It might seem more mystical than it really is because in contemporary culture we can't imagine what went without explanation in more religious cultures: that possession and appropriation is not the way to truth and wisdom. Quiet contemplation of a letting-be attitude allows aletheia, a truth of things themselves that lies beyond any captured technical truth, to be felt. But relaxed Heideggerians might be upset to find out that even a technical interpretation that understands releasement as a relaxing technique of the Asian kind can easily be derived from Heidegger's text ${ }^{4}$. Another possibility is an understanding of letting-be as postmodern "let it be" as a releasement from ideological activism of previous times, or even Paul McCartney's "Let It Be," a vision of Mother Mary healing stress and tension of making-an-album. What is obvious, however, is Heidegger's claim that European thought needs releasement, and also his personal need for releasement which would not be an admission of a kind demanded from him by Herbert Marcuse, or even Paul Celan, because these proposals were about healing the person who made a mistake, and not about its coming-out in the eyes of his public. What it should be about was healing the stress and tension of a thought itself. Releasement, among other things, occupies a place where his political activism from the beginning of the thirties used to be. Ambiguity surrounding the non-concept, and mysticism of religious origin, serve as a therapeutic relaxation of the philosophical muscles he exhibited in his National Socialist speeches, lectures and writings.

\section{Released Slovenia}

In Slovenia, Heidegger's thought had a special status from the 1960s on, when a younger generation of critical and oppositional thinkers who in the 1950s embraced existentialism, especially that of Sartre, proceeded to Heidegger. They understood Heidegger as philosopher who was able to offer a solution of intellectual independence from Marxist hegemony and political ideology, establishing the same distance from both of its Party groups: from a more fundamentalist post-Stalinist camp, and from a more liberal group which was in power at the time, but whose liberalism had much more to do with freedom of enterprise and Slovene nationalism than with human rights. Heidegger's philosophy was deep and fascinating, which means that any shallow philosophizing, as the predominant ideological style of Marxism was, could not reach nor read it, and it was critical enough to stand competition with Critical Theory, which became popular with new left movements of the

\footnotetext{
${ }^{4}$ As Michael Heim, Heidegger's American translator, comments: 'It's becoming a natural practice of things like Yoga, Tai Chi, Aikido, acupuncture, the medical theories of Chi-Gong. These practices are what might be a correlate to Gelassenheit.' (as quoted in Vezjak 2007, p. 92); it is possible to consult Heim's interview on www.mediamatic.net/page/5888/en ) as well.
} 
1960s in Slovenia as well. Heideggerianism and Western, or Critical, Marxism were the two most influential and popular ways of critical intellectual thought even during the 1970s, when poststructuralism and in Slovenia especially theoretical psychoanalysis of Lacanian interpretation, entered the field. During the 1980s, these philosophical currents influenced new post-socialist movements, but with a different accent: a Heideggerian group was involved with "New Journal" (Nova revija), a central point of intellectual and cultural movement for the multiparty system and Slovenian independence, while Post-Marxists, together with Zizek's Lacanian group, supported and joined colourful libertarian social and cultural movements which had human rights, the deideologization and demilitarization of state and civil society, and respect for constitutional legality at top of their agendas. Both sides founded a civic coalition at the end of the 1980s, at the same moment when a renewed Party leadership acknowledged that time had come to step down from power.

The story of the 1990s period, usually called a success story, includes independence, NATO and EU membership, and economic growth with social stability. But a greater part of it was in hands of the governing center-left with Liberal Democrats at the top of it, and often with ex-communists (now Social Democrats) involved. The right wing of the political, intellectual and cultural field claimed that this meant transition was not over yet, because "old forces" were still in power. Also, the importance of the cultural and ideological field for political struggles diminished radically, if compared with its visibility and influence under socialism. The position of civil society was taken over by new ownership and management who influenced politics much more than yesterday's heroes of anticommunist struggles. These issues dominated 2004 campaign for parliamentary elections held on October 3. Initiated by the civil society oppositional support group Assembly for Republic (Zbor za republiko), which emerged from "New Journal" (New Journal), Heidegger's Gelassenheit became the central political slogan for right-wing opposition to the 2004 parliamentary elections. Under this slogan they won the elections, and using this slogan a new government introduced its new style of politics. During these political events, releasement expanded into public discourse to become a common word used in any possible context, including politics, culture, economy, and even sport. To understand the meaning of this "cultural turn" of a dark, Heideggerian non-concept into a popular slogan and common discursive filler, we first have to explain its dubious translation into Slovenian language, and its aliquot meanings invading it from the spheres of psychological and alternative soultherapies.

\section{On translation}

Gelassenheit is not a word from everyday speech; that is why its English translation is releasement (or even letting-go) and not relaxedness (which in German would be Ungebundenheit, or even Unbändigkeit). Relaxedness, on the other hand, is a colloquial concept, not a concept from scientific discourse, where psychology prefers to use relaxation. In Slovenian translation, however, sproščenost was introduced for Gelassenheit, which would be analogous to an English translation of this term as relaxedness.

This blurring of releasement with relaxedness later became useful for the political turn of its meaning. With a diagnosis that transition in Slovenia was not over because left-center parties had a leading position in all coalitions from 1992 on, and that people still could not say farewell to the past, it was suggested that governing parties release their nervous grip on power, and people were asked to release their ties with the past and open a way for new, released Slovenia. "Released/relaxed Slovenia" became a political slogan of united right-wing parties that won the 2004 elections. The notion which was used to symbolize the absence of individual will in front of God's will itself, and which Heidegger secularized as a counter-concept to will to power, reappeared in Slovenia as a notion which successfully opened a way to power, and expressed will to power in a half-hidden way, representing the political will of the other as a will to power, and the will to win power of the other half of the political field as a general relaxation and letting-go of political tensions. It sounded like a national 
shrink's announcement, and became very popular, featuring a therapeutic session which expressed first the common wish to learn how to survive troubled times in a risky society and second, modernity's anxiety. Still, it seemed to be detached from reality enough to promise relaxedness without any real changes: just stop caring about it, and reality will disappear. It became the most popular and abundantly used word, not only in the media but also in everyday discourse. Heidegger's releasement - in touch with common relaxedness, misinterpreted as scientific relaxation, a stateapproved therapy for all tensions and anxieties of contemporaneity, was recognized as a universal medicine needed by all and everybody alike: "In a number of signifying uses the concept is invariably universal and therefore its functioning very simple: it explains all and at the same time remains a systematic, project-based concept" (Vezjak 2007, p. 111).

\section{Relaxedness and ski jumping}

In sport use, where the ability to relax is believed to be one of the supporting pillars of elite performance, the hybrid notion of releasement/relaxedness, with all of its mystical, philosophical, psychological and political connotation, joined the established vocabulary, but stayed there only for a short period of time. With the exception of ski-jumping, where it is even featured now, five years after its introduction, as one of the major words with secret meaning. What is so special about Slovene skijumping that it embraced and still nurtures a notion which disappeared everywhere else precisely because it was contaminated with this hybridity?

Concerning the psychological side of performance, ski-jumping is specific in itself. Besides some great jumpers who excelled more or less a decade and even longer, we could name a long list of those who "danced one winter only", and who had a lot of problems with things other than technical skill, including anorexia and bulimia, alcoholism, depression, or, at least, fear of flying and anxiety. It is a demanding sport, even with contemporary rules which take more care of jumpers' security and safe competition. It is an Olympic sport, but also an extreme sport in need of heroic stamina. And beyond all these, it needs a lot of automatic movement for any success: to jump, you have to attain over $90 \mathrm{~km} / \mathrm{h}$ in a second in an aerodynamic egg position; then, in a fraction of a second, you have to manage a complicated launching movement just at the right moment on the ramp; and if all that was right, you fly through the air for another second in a position which is expected to be relaxed but controlled, to touch the ground with another quick body manoeuvre which is meant not just to assure safe landing but also to win sometimes decisive additional style points. Duration in ski flying is a bit longer, of course, but it involves greater speed and more threatening dives, where any fear can cost you, because the most dangerous thing in ski flying is just to jump, i.e., to be too short, because landing is problematic at such short distances, and you have to get safely down along a very steep hill, but with jumping skis, not with downhill equipment. For Slovenia, it is even more so. It is "a national sport" not because there would be so many jumpers, but because the nation has identified itself with their competitions for more than 80 years already, including Planica flying, which represents a massive, annual festival of national identity, featuring a continuous ambition to break records 5 . The period of 2004-2009 is, with a short break in winter 2005 (Benkovic world champion, team with bronze), one of the longest periods of crisis, during which everything possible and impossible was tried to bring Slovene ski-jumping onto the winning path again. But because young boys enter this sport exactly for its heroic and macho image, they are reluctant to submit themselves to active psychological treatment. It diminishes their status and is believed to be something shameful: only one Slovenian ski-jumper engaged a psychologist during that period (with little success), which is really

\footnotetext{
${ }^{5}$ Ski flying originates from Planica, where Slovene Stanko Bloudek built the first ski flying hill. In 1934, competitions started there with a new world recorded by Norvegian Birger Ruud (92m). In 1936, Sepp Bradl was the first to overcome $100 \mathrm{~m}(101 \mathrm{~m})$. A new and much greater flying hill was built by the brothers Gorisek in 1969, with many new world records (from $156 \mathrm{~m}$ to $165 \mathrm{~m}$ ) set one after another during the first days of competition. In 1994, after additional work on the hill allowed further records to bet set, Toni Nieminen was the first to fly over 200m (203m). Today, world record belongs to Bjørn Einar Romøren (239m) and to Planica hill.
} 
unbelievable, if we take into account that psychological troubles were named as a main reason for their lack of success all along, and that relaxedness/releasement was named as the main goal of coaching more than thousand times by coaches, jumpers, and media commentators. All this created an atmosphere of unpredictability and helplessness that called for a publicly acceptable excuse. That may be another reason why relaxedness/releasement got such lofty status in ski-jumping discourse: there is nothing wrong with our coaching and our jumpers' will to compete, there is just a little je-ne-sais-quoi missing, and this I-do-not-know-what - an expression used to explain what makes, beside all technical matters, a work of art complete, perfect and beautiful - was covered with a word available on the market, a word which at the same time had a meaning of a mystical je-ne-sais-quoi and a serious scientific psychological approach, something as manageable in the case of soul as a kinesiological approach is in relation to body troubles. Heidegger's notion of releasement was combined with a completely technical meaning. This potential mixture and hybridity was introduced with the help of Slovenian translation, and by the initial popularity of the term in 2004. To study the use of the word sproščenost (relaxedness/releasement), I examined all ski-jumping entries (news, reports, interviews, commentaries) in the Slovenian sport daily Ekipa ("The Team") during the period 2004 (starting with November 2004) - 2009 (concluding with March 2009), as well as the use of this term. I did not start with winter season of 2004 (January - March 2009) because that was still before the elections of that year, and before the launching of the word into general public orbit, and concluded without the summer and winter season of 2009/2010, which is still going on. This examination proved that:

- the term entered sport jargon, but left it quite soon, more or less parallel with other areas of discourse, including political use;

- the term entered ski-jumping jargon too, but has remained there up to now, including the nonexamined period of summer and winter 2010;

- the term was used more in times of low or no success, and less in times of better results (which were rare during these seasons anyway);

- the term was initially used by coaches, then by ski jumpers, and finally by journalists and commentators.

During this period, there were changes in the team, and we experienced different coaches, although the initial and actual one is the same, Matjaz Zupan, and there was only one head journalist for ski jumping in Ekipa during this period (Robert Pogačar). Still, the term went on from one to another, as coaches and ski-jumpers used it in their interviews and statements, as did the journalist in his interpretation of results and commentaries. The field of ski-jumping was covered regularly and abundantly, confirming the status of the national sport, including announcements made before any event, coverage of an event, and aftermath commentaries, with regular climax in world championships, the Four Hills/New Year's Tour, and Planica ski flying competitions. Besides the aforementioned basics, there are some other features in the use and intended meaning of relaxedness/releasement .

There was repetition and stereotyped phrases in the use of the word nearly each time it was uttered: "do not care too much", "do not wish too much", "do not think about getting results", "do

\footnotetext{
${ }^{6}$ After another bad result, the team expressed its determination not to worry: 'We are dissapointed, but we will not worry about results', including an additional explanation by coach Zupan: 'You cannot force results, so lads will have to get relaxed' (both Ekipa, 20.2.2006).

${ }^{7}$ For instance, team coach Matjaz Zupan said on November 26, 2004 that 'Sometimes we get it, sometimes we fail. It happens that in spite of successful training a jumper is burried under his own wish.' (Ekipa, 26.11.2004). He repeated it in a more elaborate statement on November 29, 2004: 'Most of our competitors wish too much, they invest too much effort, they have no relaxedness. That is the biggest trouble we have to deal with now.'

${ }^{8}$ For instance, Matjaz Zupan's statement of January 3, 2005, was: 'The trouble is in heads of the jumpers who have not enough self-confidence. Thinking about the result always thickles them, and the consequence is unrelaxedness which brings out mistakes' (Ekipa, 3.1.2005). Sometimes even getting results is uncalled for: 'I do not want to rush things. If you win, than willy-nilly your head gets a bit dizzie. The victory can wait for more important moment' (Ekipa, 9.10.2007).
} 
not want it all at once", "forget about competition", "unplug your consciousness", "get relaxed, get a feeling" 10 , "and just enjoy your own jumping", , etc. These repetitions expressed a task for jumper to do his required body movements as automatically as possible, so that he could achieve his maximum performance, i.e. to be successful within professional sport ethics of maximum ${ }^{12}$. To achieve this unconscious automatic performance of technical skill acquired during training, he has to enjoy being unplugged from any conscious effort and wish; he has to be emotionally positive. He is expected to do his best without trying, but with pleasure and delight, the result of a non-competitive approach that silences any competitive expectations. As a professional elite athlete, he has to reach his maximum performance by forgetting about his maximum performance, and enjoy it at the same time as some amateur recreational jumper would do - if there could exist such creature as a recreational jumper. ${ }^{13}$ All this together describes the ultimate paradox and ideal of elite sport kinesiology: a human machine unplugged from any conscious control, with a psychical attitude of enjoyment but without will and effort. Heidegger's releasement is quite near to such an attitude, but it contains no will at all because it is on the other side of any possible achievement, victorious performance or winning attitude: it is a letting-be for the truth of things themselves. When you transport it to elite sport, releasement is not your letting-be giving voice to the truth of things themselves, but to the world of technique. This describes the ideal athlete: he or she has to open their will to God, i.e., to be controlled not by their own consciousness but by scientifically acquired technique repeated automatically, without conscious effort and competitive tension, on and on. Moreover, in such a state, they are expected to be at the disposal of institutionalised sport structures as their willing object without a will of their own: Hobbes' Leviathan could best illustrate an elite sport commonwealth. What they tried to do was to transplant mystical releasement, which means to forget about your own will for control over the world of being, into a paradoxical technique for getting the best results in winning over the elements and the other competitors: to turn the silencing of your own ego into a technique for winning over the other egos and natural circumstances of being. Perfect biomechanics is the ideal of kinesiology which, however, could be reached only at the expense of consciousness and will, turning your own self into a machine. This machine is still enjoying itself without feeling pressure or wilful effort. It goes without saying what kind of understanding could such prescriptions trigger with young men choosing ski jumping as their sport: from the post-modern youth culture they know very well what a relaxed attitude of not caring and letting be could be, and what it means to be completely unplugged and detached. They do not get rid of pressure; they just behave as if they would not care about competition and results, feeling that if you really want something you have to make an impression that you are indifferent to it. And that is what they demonstrated, not only with their statements but with their body language as well: "Did I fail again? I could care less about it." The problem was that Slovenian ski jumping fans, sponsors and officers could not get as relaxed about the results as the competitors did, and all of them were constantly reminded that releasement, demonstrated in this enjoyment bad results, is the right way to success. Or, as jumpers and their coaches repeatedly stated: "The problem is in the head." And this "problem in the head" is that kinesiology's approach is able to control all movements, turning jumpers into human machines - but for their heads where a will to win and a fear of pressure represent a deadly mixture. Paradoxically, the approach to this problem is to eradicate all control from your

\footnotetext{
${ }^{9}$ Rok Benkovic informed his fans after big success that 'Zupan says that crisis occurs if a jumper starts to jump consciously, and that is why we train each day, so that we could jump sub-consciously' (Ekipa, 24.2.2005).

${ }^{10}$ After Rok Benkovic's world champion title of 2005, Matjaz Zupan said: 'Relaxedness has been rewarded' (Ekipa, 21.2.2005). On next day (February 22, 2005), another jumper Tepez said that 'In jumping it is often that you need just a tiny moment to get a feeling, and then everything follows as you wish' (Ekipa, 2.2.2005).

${ }^{11}$ Jure Bogataj, who entered international high class compeititons as a new hope of Slovene ski-jumping in 2004, said later during that season: 'I arrived in the World Cup completely relaxed, and wished primarily to enjoy myself. I was not under pressure of achieving results' (Ekipa, 9.2.2005).

${ }^{12}$ Ethics of maximum (Miller, Sumic Riha, Hosta).

${ }^{13}$ Eddie "the Eagle" Edwards was quite near this, but today it is not possible to even enter the competition if you jump like he did, and he was not recreational jumper, because he trained as seriously as anybody else.
} 
head. Who controls your jumping then, if you are personally unplugged from your head, as a zombie enjoying his zombiness? Sport science itself. You are not free from technique as approach to objects, you become a thing completely submitted to technique, your own self unplugged but for a happy smile. You enter the Democritus world of mechanical determination, a world without freedom, but you have to enjoy it as if being in an Epicurus world of unpredictability. Jumpers were not dealing with their performance but with an impossible task to become free of charge, and that is what they became: charged with getting free of charge, burdened with un-burdening themselves from their charge. Torn between releasement and relaxedness, but without a psychologically plausible approach of relaxation techniques, they got lost in translation. Psychological training may have helped, of course, but they did not engage in it, or without a systematic approach. Obviously, the majority of the team and its coaches wanted "releasement" to remain an un-revealed secret, a mystical and unscientific approach. Was that because of a rivalry between psychology and kinesiology, or for sociocultural reasons of shameful psychological treatment? During five years of mostly meagre results, not even one of them said: "I was completely relaxed, but I still could not perform well." On the other hand, they were ensnared in a paradox: a jumper has to consciously accept a kind of personality transformation ${ }^{14}$ which includes the elimination of secondary motivation (victory, results, success, glory) and brings to the front primary motivation (to enjoy), but without any conscious effort or pressure: as you have to reduce yourself to non-consciousness, there is necessarily somebody or something else who or which will transform your personality. It seems that efforts of releasement in ski jumping calls for flirting with Donald Ewen Cameron's model of distorting the original personality of the ski jumper, without his methods, but by opening jumpers' minds to external intervention due to their quest for success, glory and heroic status. Yes, the problem was indeed in the head, and that is the real problem of contemporary science which is the head of sport. It has two sublime purposes: how to produce machines who think as humans do, and humans which enjoy being machines.

\section{REFERENCES}

Ekipa (Slovene sport daily newspaper) 2004-2009.

Heidegger, M. (1966). Discourse on Thinking. New York: Harper and Row.

Heidegger, M. (2010). Country Path Conversations. Bloomington: Indiana University Press (in print).

Heidegger, M. (2004). Pogovori s poljske poti. Ljubljana: Društvo Apokalipsa.

Marcuse, H. (1998). Heidegger and Marcuse: A Dialogue in Letters. Technology, War, and Fascism (pp. 263267). Routledge: London.

Milner, J.-C. (1992). Constat. Paris: Gallimard 1992.

Riha-Šumič, J. (2002). Mutacije etike. Ljubljana: Založba ZRC.

Vezjak, B. (2007). The Relaxed Ideology of the Slovenes. Ljubljana: Mirovni inštitut (published in English and Slovene).

\section{AUTHOR'S ADDRESS: $\quad$ Lev Kreft}

University of Ljubljana

Department of Philosophy - Faculty of Arts

Askerceva 2, 1000 Ljubljana, Slovenia

Email: lev.kreft@guest.arnes.si

\footnotetext{
${ }^{14}$ Matjaz Zupan in Ekipa ( 3.3.2005).
} 